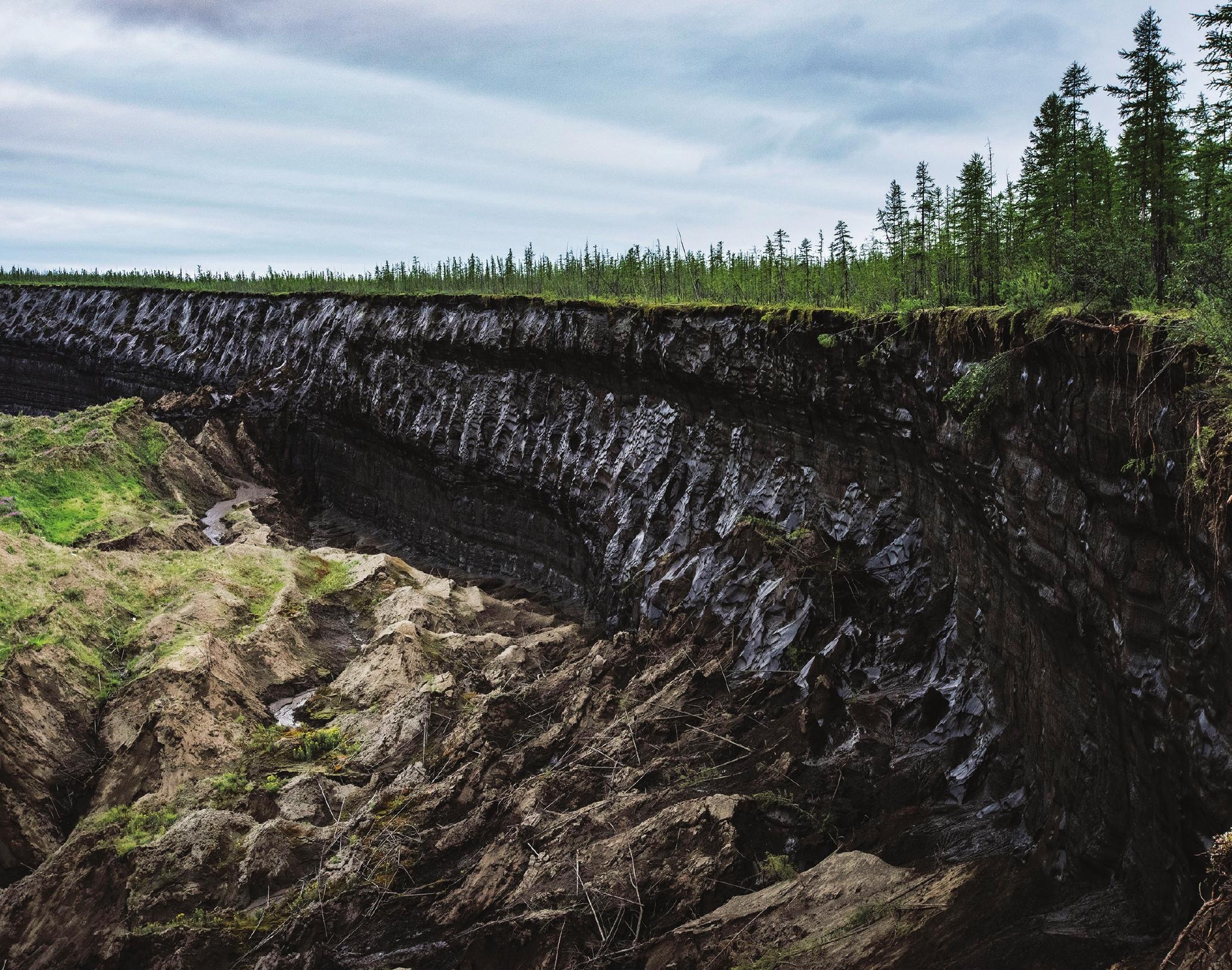

The Batagaika crater in eastern Russia was formed when land began to sink in the 1960 s owing to thawing permafrost.

\title{
Permafrost collapse is accelerating carbon release
}

The sudden collapse of thawing soils in the Arctic might double the warming from greenhouse gases released from tundra, warn Merritt R. Turetsky and colleagues.

$\mathrm{T}$ This much is clear: the Arctic is warming fast, and frozen soils are starting to 1 thaw, often for the first time in thousands of years. But how this happens is as murky as the mud that oozes from permafrost when ice melts.

As the temperature of the ground rises above freezing, microorganisms break down organic matter in the soil. Greenhouse gases - including carbon dioxide, methane and nitrous oxide - are released into the atmosphere, accelerating global warming. Soils in the permafrost region hold twice as much carbon as the atmosphere does - almost 1,600 billion tonnes ${ }^{1}$.

What fraction of that will decompose? Will it be released suddenly, or seep out slowly? We need to find out.

Current models of greenhouse-gas release and climate assume that permafrost thaws gradually from the surface downwards. Deeper layers of organic matter are exposed over decades or even centuries, and some models are beginning to track these slow changes.

But models are ignoring an even more troubling problem. Frozen soil doesn't just lock up carbon - it physically holds the landscape together. Across the Arctic and Boreal regions, permafrost is collapsing suddenly as pockets of ice within it melt. Instead of a few centimetres of soil thawing each year, several metres of soil can become destabilized within days or weeks. The land can sink and be inundated by swelling lakes and wetlands.

Abrupt thawing of permafrost is dramatic 
to watch. Returning to field sites in Alaska, for example, we often find that lands that were forested a year ago are now covered with lakes ${ }^{2}$. Rivers that once ran clear are thick with sediment. Hillsides can liquefy, sometimes taking sensitive scientific equipment with them.

This type of thawing is a serious problem for communities living around the Arctic (see 'Arctic permafrost'). Roads buckle, houses become unstable. Access to traditional foods is changing, because it is becoming dangerous to travel across the land to hunt. Families cannot reach lines of game traps that have supported them for generations.

In short, permafrost is thawing much more quickly than models have predicted, with unknown consequences for greenhouse-gas release. Researchers urgently need to learn more about it. Here we outline how.

\section{TWICE THE PROBLEM}

Permafrost is perennially frozen ground. It is composed of soil, rock or sediment, often with large chunks of ice mixed in. About one-quarter of the land in the Northern Hemisphere is frozen in this way. Carbon has built up in these frozen soils over millennia because organic material from dead plants, animals and microbes has not broken down.

Modellers attempt to project how much of this carbon will be released when the permafrost thaws. It is complicated: for example, they need to understand how much of the carbon in the air will be taken up by plants and returned to the soil, replenishing some of what was lost. Predictions suggest that slow and steady thawing will release around 200 billion tonnes of carbon over the next 300 years under a business-asusual warming scenario ${ }^{3}$. That's equivalent to about $15 \%$ of all the soil carbon currently stockpiled in the frozen north.

But that could be a vast underestimate. Around $20 \%$ of frozen lands have features that increase the likelihood of abrupt thawing, such as large quantities of ice in the ground or unstable slopes ${ }^{2}$. Here permafrost thaws quickly and erratically, triggering landslides and rapid erosion. Forests can be flooded, killing large areas of trees. Lakes that have existed for generations can disappear, or their waters can be diverted.

Worse, the most unstable regions also tend to be the most carbon-rich ${ }^{2}$. For example, 1 million square kilometres of Siberia, Canada and Alaska contain pockets of Yedoma - thick deposits of permafrost from the last ice age ${ }^{4}$. These deposits are often $90 \%$ ice, making them extremely vulnerable to warming. Moreover, because of the glacial dust and grasslands that were folded in when the deposits formed, Yedoma contains 130 billion tonnes of organic carbon - the equivalent of more than a decade of global human greenhouse-gas emissions.

How much permafrost carbon might be

released with abrupt thawing? As a first step, this year we synthesized results from published studies of abrupt thawing across the permafrost zone. We asked how this type of thawing influences plants, soils and moisture in the ground. The studies revealed patterns of collapse and recovery. This international project was supported by the Permafrost Carbon Network (www.permafrostcarbon.org), part of the multimillion-dollar global Study of Environmental Arctic Change (SEARCH).

Lakes and wetlands are a big part of the problem because they release large amounts of methane, a greenhouse gas that is much more potent than $\mathrm{CO}_{2}$ (ref. 5). Erosion from hills and mountains is also problematic: when hillsides thaw and break up, much $\mathrm{CO}_{2}$ is released as material is destabilized, decomposed or washed into streams or rivers ${ }^{6}$.

We estimate that abrupt permafrost thawing in lowland lakes and wetlands, together with that in upland hills, could release between 60 billion and 100 billion tonnes of carbon by 2300 . This is in addition to the 200 billion tonnes of carbon expected to be released in other regions that will thaw gradually. Although abrupt permafrost thawing will occur in less than $20 \%$ of frozen

\section{"Understanding abrupt thawing must be a research priority."}

land, it increases permafrost carbon release projections by about $50 \%$. Gradual thawing affects the surface of frozen ground and slowly penetrates downwards. Sudden collapse releases more carbon per square metre because it disrupts stockpiles deep in frozen layers.

Furthermore, because abrupt thawing releases more methane than gradual thawing does, the climate impacts of the two processes will be similar ${ }^{7}$. So, together, the impacts of thawing permafrost on Earth's climate could be twice that expected from current models.

Stabilizing the climate at $1.5^{\circ} \mathrm{C}$ of warming ${ }^{8}$ requires massive cuts in carbon emissions from human activities; extra carbon emissions from a thawing Arctic make that even more urgent.

\section{RESEARCH GAPS}

Our estimates are rough and need refining. However, they show that understanding abrupt thawing must be a research priority.

First, climate and soil scientists need to find out where the greatest emissions of methane and $\mathrm{CO}_{2}$ will come from. Although we have a good idea of current numbers of thaw lakes and wetlands ${ }^{9}$, and how many existed in the past $^{10}$, we need to be able to project where new ones will appear. We also need to know how quickly they will drain as the climate warms.

Second, the erosion of thawed soils on hillsides is poorly understood. Because collapsing slopes are hard to detect using satellites, only a few large-scale studies have been done, often using data from oil exploration or road surveys. Researchers need to establish how much permafrost carbon is displaced and what happens after it has thawed. For example, it is not known how much will stay in the ground or be buried, and how much will enter the atmosphere as a greenhouse gas ${ }^{11,12}$. And what happens to this material if it flows into rivers, lakes and estuaries?

Third, we need to identify the extent to which plant growth will offset the carbon that is released by permafrost ${ }^{3}$. Over time, lakes are invaded by wetland plants, and eventually drain and convert back to tundra. Eroded areas are colonized by plants, which helps to stabilize soils and speed their recovery. Researchers need to monitor how thawed ecosystems evolve, the rate at which vegetation stabilizes, and how these plants accumulate biomass. Vegetation also responds to rising $\mathrm{CO}_{2}$ and nutrients, longer growing seasons and changing levels of soil moisture. Modellers will need to predict changing feedbacks between ecological communities and geomorphology as permafrost landscapes transform.

Fourth, the distribution of ice in the ground is the main factor influencing the fate of permafrost carbon. Yet observations of ground ice are sparse. More-widespread geophysical measurements could map pockets of ice below the surface, revealing where it concentrates and how quickly it melts. Machinelearning techniques might even be developed to predict where most ice is buried, by analysing soils and topography at the surface.

\section{NEXT STEPS}

To plug these knowledge gaps, we have five recommendations.

Extend measurement technology. There should be better tracking of permafrost and carbon across the Arctic, especially in regions undergoing abrupt thawing. It is important to establish baselines of permafrost and ecosystem change against which future measures can be compared. This will require aircraft-based lidar (light detection and ranging, a surveying technique that uses pulsed laser light), drone-based surveys and better algorithms for image analysis.

Fund monitoring sites. River chemistry can be a sensitive indicator of abrupt thawing, but many monitoring stations are being abandoned $^{13}$. Instead, there should be increased national and international investment in long-term sites that link land-based observations with aquatic and marine measurements. Better recordings of organic matter and nutrients in rivers would shed light on how permafrost plant and microbial communities respond to abrupt and gradual thawing.

Gather more data. Regions that are vulnerable to abrupt thawing need more 


\section{ARCTIC PERMAFROST}

One-fifth of frozen soils at high latitudes are thawing rapidly and becoming unstable, leading to landslides and floods that release carbon into the atmosphere.

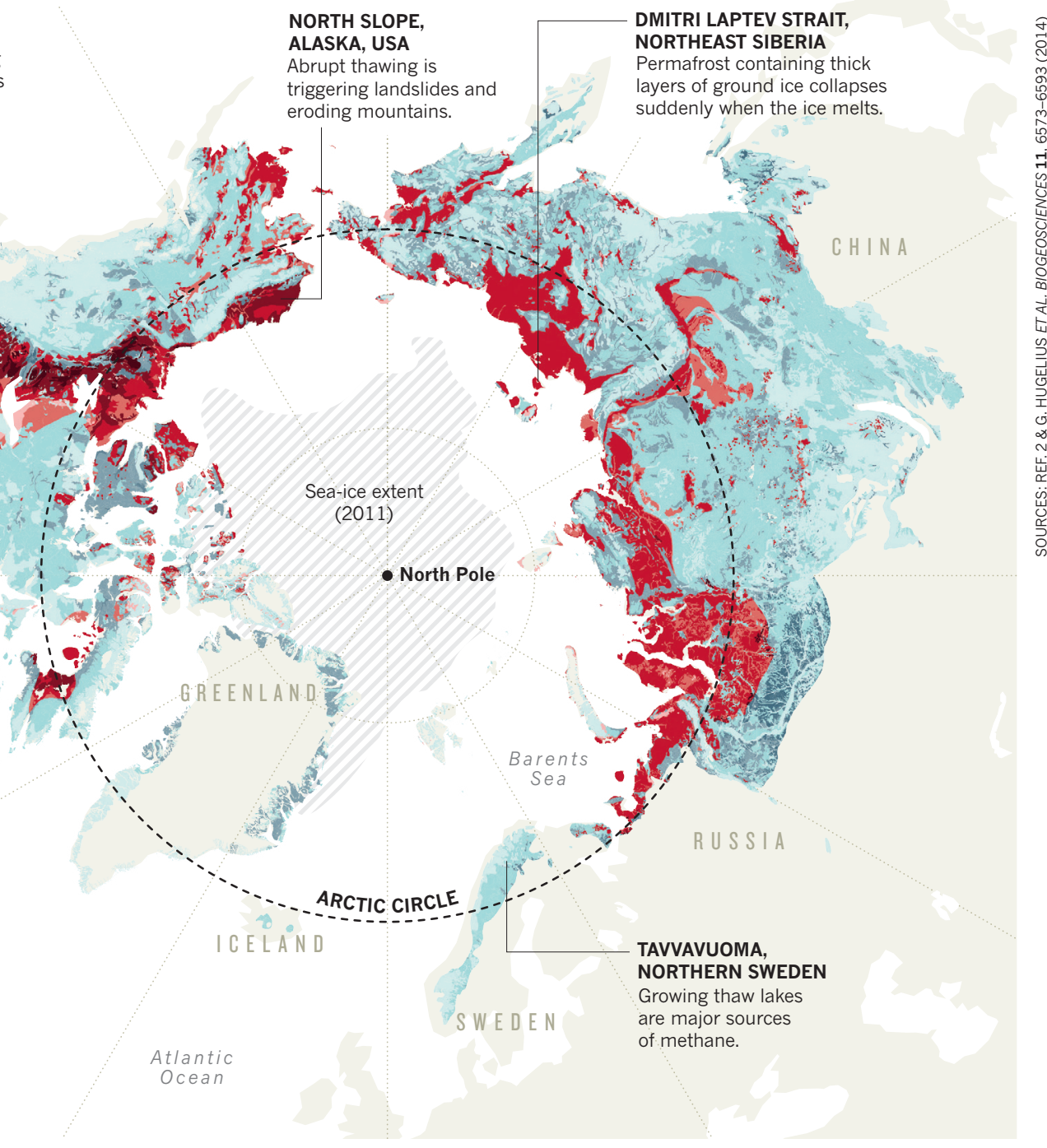

of unresolved climate feedbacks, as the Intergovernmental Panel on Climate Change (IPCC) did for gradual thawing in its 2018 special report $^{8}$. The Permafrost Carbon Network is contributing to such efforts, for example by ensuring that abrupt thawing is characterized in the IPCC's Special Report on the Ocean and Cryosphere in a Changing Climate, which will be released later this year.

We can't prevent abrupt thawing of permafrost. But we can try to forecast where and when it is likely to happen, to enable decision makers and communities to protect people and resources. Reducing global emissions might be the surest way to slow further release of permafrost carbon into the atmosphere ${ }^{3}$. Let's keep that carbon where it belongs - safely frozen in the stunning soils of the north.

Merritt R. Turetsky is a Canada Research Chair in the Department of Integrative Biology, University of Guelph, Canada. Benjamin W. Abbott, Miriam C. Jones, Katey Walter Anthony, David Olefeldt, Edward A. G. Schuur, Charles Koven, A. David McGuire, Guido Grosse,
Peter Kuhry, Gustaf Hugelius, David M. Lawrence, Carolyn Gibson, A. Britta K. Sannel. e-mail:mrt@uoguelph.ca

1. Schuur, E. A. G. et al. Nature 520, 171-179 (2015).

2. Olefeldt, D. et al. Nature Commun. 7, 13043 (2016).

3. McGuire, A. D. et al. Proc. Natl Acad. Sci. USA 115, 3882-3887 (2018).

4. Strauss, J. et al. Earth-Sci. Rev. 172, 75-86 (2017).

5. Walter Anthony, K. M. et al. Nature Commun. $\mathbf{9}$ 3262 (2018)

6. Abbott, B. W. \& Jones, J. B. Glob. Change Biol. 21, 4570-4587 (2015).

7. Koven, C. D. et al. Phil. Trans. R. Soc. A $\mathbf{3 7 3}$ 20140423 (2015).

8. Rogelj, J. et al. in Global Warming of $1.5^{\circ} \mathrm{C}$ (eds Masson-Delmotte, V. et al.) Ch. 2 (IPCC, 2018).

9. Nitze, I., Grosse, G., Jones, B. M., Romanovsky, V. E. \& Boike, J. Nature Commun. 9, 5423 (2018).

10. Treat, C. C. et al. Proc. Natl Acad. Sci. USA 116, 4822-4827 (2019).

11.Vonk, J. E. et al. Geophys. Res. Lett. 40, 2689-2693 (2013).

12.Abbott, B. W., Jones, J. B., Godsey, S. E., Larouche, J. R. \& Bowden, W. B. Biogeosciences 12, 3725-3740 (2015).

13. Laudon, H. et al. Nature Geosci. 10, 324-325 (2017).

Disclaimer: Any use of trade, product or firm names is for descriptive purposes only and does not imply endorsement by the US government. 